\title{
Practices of Childcare in Urban China The Making of Competent Mothering in Beijing
}

\section{By Michala Hvidt BreengaArd}

\begin{abstract}
Practices of Childcare in Urban China. The Making of Competent Mothering in Beijing

Over the past decades, China's one-child policy and broader modernization project has paved the way for scientific approaches to childcare. While the emphasis on expert-led childcare promotes new practices of mothering, it also acts as a differential between those who are able to carry out these practices and those who are not. Taking its point of departure in the concept of intersectionality and in post-structural theories of subjectification, this article explores how mothers and child professionals in contemporary Beijing draw boundaries between those considered competent and incompetent in childcare. By analysing their stories on infant feeding, the article finds that older generations and rural people are demarcated as lacking new knowledge and thereby positioned as incompetent, while well-educated mothers are positioned as highly competent. However, the article also suggests that these positions are not stable but contain potentials for transformation.
\end{abstract}

\section{KEYWORDS}

Infant feeding, quality (suzhi), expert-led childcare, mothering

Michala Hvidt Breengaard is a PhD fellow at Department of Sociology, University of Copenhagen and at the Sino-Danish Centre, a Chinese-Danish research initiative. Her research project explores the practices of mothering that followed the one-child policy in urban China. 


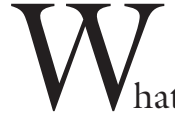

to be a competent mother in contemporary urban China? In one of the interviews I conducted with well-educated mothers and child professionals, Lu Meili, ${ }^{1}$ mother of a four-month-old baby, indicated how mothers' competence is closely linked to their ability to acquire knowledge: "In my opinion, you must have a lot of knowledge to be a good mother. If you have a lot of knowledge, your ideas will be different." This view was not unique. In fact, it resonated through all the interviews I conducted in Beijing between 2012 and 2014. What became of particular interest to me, was how the interviews revolved around expert knowledge as a difference-maker that not only designated good and proper care approaches, but also identified who were competent and incompetent in matters of childcare and mothering. I believe these distinctions should be understood in a broader differential system that followed in the wake of the Chinese population project and the discourse about 'quality children' (Milwertz 1997). During the past decades, the need for 'quality children' has been framed as the key to China's future development, the demand on mothers being to reproduce less but nurture better (Anagnost 1997: 214). This framing has transformed national goals of modernity into desires of good childcare within the family (Woronov 2007). Not only have these desires promoted new approaches to childcare and encouraged parents to consult the growing supply of expert literature, they have also established boundaries between those who conform to these practices and those who do not (Kipnis 2006; Anagnost 2004).

As it is played out in China, the concept of quality (suzhi) has set up differentiated accesses to socially desired identities, dividing humans into categories of low and high quality, backward and advanced, traditional and modern (Greenhalgh 2003). In this article, I am particularly concerned with how these boundaries unfold on the level of lived everyday life. I explore how mothers are acting on the new ideals of childcare as well as which mother is considered competent to make a quality child. I base my analysis on stories about infant feeding as they unfolded in the interviews I did with 22 well-educated mothers of young infants as well as eight child professionals. All mothers had intended to breastfeed and all professionals were strong supporters of breastfeeding. This might not be surprising as initial contact with both mothers and professionals was made through a mailing list of the local Beijing branch of La Leche League, an international NGO that helps mothers to breastfeed. ${ }^{2}$ Their stories of feeding practices go far beyond simple requirements of nutrition and reach out to broader meanings of the worth of mothers and other caregivers. I approach their stories of infant feeding as part of a narrative self-construction that mothers and professionals engage in while seeking to foster a quality child (Faircloth 2009: 15). Drawing upon the concept of intersectionality as well as post-structural theories of subjectification, I examine how the stories draw boundaries between different categories that place some subjects at the periphery of competent childcare, while placing others central. I argue that well-educated mothers are positioned as being highly qualified, while others, especially grandparents and nannies, are demarcated as incompetent. However, I find that these subjectivities are not fixed but are able to transform from incompetent to competent.

I start with a brief introduction to broader implications of feeding infants in urban China and then go on to clarify my theoretical approaches. In the following analysis, I am mainly concerned with three questions. First, how can we understand 
the relation between fostering a quality child and becoming a competent mother as a lived experience? Second, how are certain categories demarcated as competent/ incompetent? And third, how does the competent mother emerge through this boundary-making in present day China?

\section{FEEDING INFANTS IN URBAN CHINA}

In China, as elsewhere, infant feeding is a complex area, touching upon tradition and modernity on broader societal levels as well as in everyday lived life. On the one hand, milk has become a symbol of modern, scientific and urbanised Chinese life, the consumption of milk figuring as a link between a "globalised and modern lifestyle" and the "quality of the nation" (Ross 2002: 38). The boom of the formula market and advertising has meant an increased consumption of milk powder at the expense of breastfeeding (Qiu et al. 2008). On the other hand, China has faced severe incidents of contaminated infant formula resulting in illness and even death among infants. Milk features as both nourishing the child and a modern self, and also as potentially endangering them. And this is not only true for the consumption of infant formula. Recent and especially Western studies have extended the symbolism of milk to encompass breastfeeding too, pointing to breastfeeding as a moral imperative that arose with a discourse of expertled, child-centred parenting, especially targeting middle-class motherhood (see e.g. Avishai 2007; Kukla 2006; Law 2000). The mothers I interviewed are part of this target group. Almost all of them had university degrees and worked in white-collar jobs. They were, as we shall see, very inclined towards expert knowledge. This form of knowledge was in many ways represented by the child professionals I interviewed. Four of them worked in hospitals as midwives, nurses or paediatricians; one was a breastfeeding advocate and leader of a breastfeeding community; another was a teacher; one worked as a radio host, broadcasting on child education among other things; and the last was employed in an international NGO. It was this type of professionals that mothers would consult and often refer to as experts.

In recent decades, the Chinese Ministry of Health has followed global standards for promoting breastfeeding by initiating a number of breastfeeding campaigns. This recommendation to breastfeed is related to broader actions to ensure that all children born under the one-child policy are healthy (Chamberlain 1997). The rhetoric in these campaigns presents breastfeeding as the scientific way of feeding. The Chinese Action Program on Child Development calls, for instance, for actions to "raise the quality of newly born babies". This is followed by encouragements to "[a]dvocate scientific ways of feeding and good diet habits to improve the condition of child nutrition. Support breast-feeding" (NPA 2001-2010). The emphasis on science is repeated in the subsequent action program, which provides encouragement to “upgrade parents' scientific infant-feeding knowledge" (NPA 2011-2020). The inclination towards science in areas of childcare has drawn the attention of several scholars, who argue that the one-child policy has led parenting towards more scientific and 'modern' approaches, especially among the urban, middle-class (Naftali 2010; BinahPollak 2014; Anagnost 2008; Gottschang 2000). Orna Naftali (2010) points to how the lite-rature on childcare has grown exponentially over the past decades, and Suzanne Gottschang (2000) shows how breastfeeding in Beijing is promoted as a modern way of feeding infants. Yet, even if global and national health institutions describe breastfeeding as the 'safe' or 'best' choice, mothers might face difficulties in breastfeeding successfully or might encounter other interpretations of the maternal body and infants' food that do 
not accept the superior benefits of breastfeeding. For instance, throughout the Chinese history, mother's milk has had a dubious reputation as varying in quality and therefore a substance that could either benefit or endanger the infant (Hsiung 1995). These understandings of breast milk as potentially dangerous co-exist with the declarations that link breastfeeding to modern mothering. As such, practices around infant feeding relate to broader ambitions and to ambi-guities of modernity in the context where I did my interviews.

\section{Processes of SUBJECTIFICATION}

I was looking for an analytical approach that could help me understand how the boundaries that appeared in my interviews worked to include some caregivers as competent while excluding others. My interest was especially in how certain categories emerged from the stories I was told by mothers and professionals, and how these categories were assigned either qualification or suspicion in matters of childcare and particularly infant feeding. To achieve my aims, I combine the concept of intersectionality with post-structural theories of subjectification. Intersectionality emphasizes how different social categories, such as gender, class and age, are entangled in people's everyday experiences and constitute their life opportunities - or lack thereof (Crenshaw 2006). The approach offers a way to explore how the intersection of certain categories positions some people differently than others; that no category operates alone in constituting identities (Phoenix 2006: 23). In order to understand how some caregivers pass with more ease than others, I am interested in how power works in these intersections. In a theoretical adjustment of the intersectional approach, Dorthe Staunæs and Dorte Marie Søndergaard (2006) draw attention to that it is not only minorities that are constructed through certain intersecting components; majorities are also constituted through similar processes, though through different intersecting categories. This point is particularly important as I am interested in the making of norms, i.e. how norms are practiced by the urban, well-educated mothers and professionals I interviewed. Moreover, my concern is not just how certain groups are oppressed or how one group has power over another - an approach that implies a rather one-directional perception of power - but how categories might intersect in new ways that offer the subject different opportunities.

Drawing upon the work by Michel Foucault, Staunæs has studied how norms and normative deviations come into being in everyday lived life. In her work, deviants stand as certain troubled subjectivities, where 'troubled' refers to "difficult positions in both social and discursive practices" (Staunæs 2003b: 104). Troubled subjectivities - or subject positions - are demarcated figures that appear at the periphery of what is desirable (Staunæs 2003a: 16). While the notion of troubled subjectivities covers the positions that challenge norms in everyday life, i.e. describes subjects outside or on the margin of competence, I am inspired by Judith Butler's notion of the 'intelligible' to capture subjectivities that conform to the social norms (Butler 2008). In my analysis, intelligible subjects are those who act in accordance with categories of recognition and thus those who pass as competent with relatively ease. Although intelligibility is not fixed or universally the same, the intelligible subject in Butler's theorization appears fairly stable, for instance expressed in the heterosexual matrix (Butler 1990: 208), with little opportunity of including other, less intelligible categories. I am critical of this sense of a stable subject (a stability of categories that Aihwa Ong also criticizes in her conceptualization of assemblages - see interview with Ong in this issue). In fact, my analysis shows a greater complexity where 
the caregivers do not necessarily stay fixed as incompetent but might move in and out of competence.

A similar reservation as regards the stability of identity is found in Staunæs' (2003b) elaboration on intersectionality. She argues that the theory of intersectionality often fixes categories at a theoretical, determinant level, while the experiences of actual subjects appear more nuanced. In lived life, social categories are not closed or delimited, but marked by relations and meanings in the concrete and complex setting where they unfold. It follows that intersecting categories cannot be defined in advance; they are not already there as static entities, but need to be situated as a doing in the particular context being studied (Staunæs 2003b: 105). In my analysis, I approach the formation of subjectivities as a narrative process in the sense that narratives do something. They construct meaning and produce subjects. As Nira YuvalDavies suggests, narratives are processes of being and becoming, of belonging or of longing to belong, dualities that are often reflected in narratives. "Identities are narratives, stories people tell themselves and others about who they are (and are not)" (Yuval-Davies 2006: 202). But now, let us look at how categories and subjectivities unfold in the narratives of mothers and professionals.

\section{FEEDING QUALITY INTO THE CHILD}

In order to provide an understanding of how practices of childcare link to a discourse of quality children in everyday lived life, I am, in the following section, interested in the relation between the competent mother and the quality child. Scholars have pointed to a mutual meaning-making between mother and child in which the conceptions of mother and child become constructed and defined in relation to each other (see Bäck-Wiklund 1999: 198). Exactly how these constitutive relations are expressed or given meaning is, of course, a matter dependent on context. By analysing the stories of mothers and professionals, I find that the competent mother appears in narratives of healthy children, while the incompetent mother arises through an endangering of the infant. That is, we see the beginning of a narrative self-making where some caregivers pass with more ease than others.

A dominant story in my interviews revolved around the ambition of nursing a healthy child (see also Gottschang 2001). Mothers often referred to conversations with neighbours that involved comparison of their babies' health, and, as the interviews proceeded, I came to understand how the quality of babies was influenced by the way they were fed. A chubby baby was a sign of good quality, an appearance that apparently was easier to reach with infant formula, as people told one mother, "put your baby on formula and he will put on a lot of weight, look chubby and cuter". Yet, such an opinion could be countered by telling how seldom the child was ill, something which the mothers linked to breastfeeding. A general story was that formulafed babies became "much bigger in size", as several mothers explained, but also that this size masked poor quality. One mother, Chen Daiyu, expressed it like this:

they might be big but when you touch them, they are soft, if you touch them they are not firm in the flesh, I don't know if it's scientific, but it seems to be a popular conception that if you feed a baby formula, then the baby is sort of fake chubby, not real sort of meat.

While all the professionals and mothers I interviewed agreed that breastfeeding was the best, this was not always the message that mothers received from neighbours, family members or even doctors in the Chinese health system. It was these different perceptions of feeding practices that particularly motivated boundary-drawing stories 
of right and wrong, competent or incompetent. In an interview, a paediatrician formulated a link between what she saw as an incorrect feeding method and a damaged child, explaining how mothers:

... come to me and say 'well, I did mixed feeding, because the doctor recommended that I give formula' because they [some Chinese doctors] don't think breastfeeding is enough by itself and then I spend up to an hour educating them and try to get them to understand that what they were told was wrong and that not only is breast milk [the best] they can give, but that formula is actually doing damage to their babies' bodies, permanent damage for the rest of their lives.

In the paediatrician's demarcation of 'being told wrong', we get an insight into how certain feeding practices are believed to endanger the child. It is not surprising that mothers who practiced this way of feeding occupied rather troubled positions in the eyes of the paediatrician. As such, feeding practices affected not only the child but also the status of the mother. Below I look more into how the mothers practise infant feeding and the positions that these practices make available.

One mother, Xi Zhilan, expressed her ability - and success - in making her child healthy, explaining how "the hospital provided us with different standards to measure the health of our baby, and I know that my quality of milk is good because according to all the standards she is very healthy". While Xi Zhilan succeeded in adding quality to her child, another mother, Li Jiaying, appeared more challenged. In a story about a home visit by a health professional, Li Jiaying, recounts how the health visitor found her baby "so thin", and how Li Jiaying was questioned and felt treated like a "guilty criminal". Li Jiaying describes how the health visitor examined her breasts, saying: "'Let me just look at your breasts,' and she just, you know, squeezed it saying 'no, you are so poor, you can't do pure breastfeeding, you can't do it'". The critique by the health visitor can be read as a positioning of $\mathrm{Li}$ Jiaying that makes it difficult for her to pass as competent. However, Li Jiaying is not willing to accept this position. Instead, she challenges the expertise of the health visitor and, by writing her off as "unprofessional", ends up asking her to leave. While Li Jiaying is apparently able to resist the troubled position, another mother, Lu Xiaolian, finds it difficult to get rid of this position. Lu Xiaolian did not manage to breastfeed her baby during the first months and, as the baby did not gain enough weight, she felt herself more and more incompetent:

I felt wronged and helpless, because no doctors and nurses told me how to feed my baby. They just criticised me during the body check. At that time, I felt quite incapable. During that time, I even doubted my quality of being a mum.

The mothers' stories not only show how infant feeding affects the child's quality but also how the quality of their children affects the mothers' position. Besides, we see how the stories touch upon expertise as a dominant - though not determinant power in these positionings. This supports Gottschang's finding that although different understandings of feeding practices co-exist in urban China, the government's promotion of breastfeeding as scientifically approved has had the effect that urban mothers increasingly have come to rely on expert knowledge (Gottschang 2000: 160). In the following, I look more closely at how expert knowledge has become crucial in the distinctions between the competent and the incompetent in matters of childcare.

\section{BOUNDARY FIGURES}

Breastfeeding has been promoted as the 
natural way', and both mothers and professionals used this expression to explain their choice of feeding. While naturalness is a way to explain why women ought to perform certain reproductive responsibilities (Butler 1993: 33), gender alone does not explain who is regarded competent in childcare. The categories that come to matter in the following analysis are kept close to the stories of mothers and professionals. I am, for instance, not particularly interested in categories of gender. Although I initially tried to open up this area by offering the mothers and professionals opportunities to speak about differences between mothers' and fathers' care practices, stories relating to these differences were rather hard to come by. It was quite a different matter when stories touched upon care practices of grandparents or nannies. In the following two sections, I explore how grandparents and nannies are placed in the margin of competence or, to use a concept borrowed from Staunæs (2005), become 'boundary figures'.

The mothers' stories often touched upon how they had prepared to become a mother, how they acquired information and whom they trusted in matters of childcare. Grandparents occupied a significant position in these stories. This might not be surprising, since grandparents in China often take part in childcare (Goh 2011), and most of the mothers I interviewed lived with or depended on grandparents on a daily basis. Yet, I was surprised to find that these stories repeatedly described grandparents as troublesome. Mothers often talked about the differences between themselves and the older generation, or how they would not rely on their advice. As one mother, Xi Zhang, expressed it, "our parents are very old. And the knowledge about childcare from our parents cannot keep up with the new ideas. They still hold onto old ideas. There is no help."

It was not only the mothers who regarded the grandparents' knowledge as insuffi- cient. Often professionals pointed out grandparents as those who especially promoted wrong feeding methods. When mothers and professionals talked about the problems of grandparents, the category that seemed important was age. On the one hand, age was not necessarily seen as troublesome as some grandparents were seen as competent, often expressed as being able to consult books on childcare or check care practices at the internet. On the other hand, grandparents were repeatedly positioned as 'too old.' As we see in the interview excerpt above, old age became troublesome in relation to the status of knowledge. Mothers explained how grandparents practised childcare using an old paradigm, how they had "old opinions" or "traditional ideas", and how their knowledge could not be trusted. The stories about grandparents' out-dated knowledge was expressed as a distinction between the 'backward' and the 'new', a distinction that, as Susan Greenhalgh suggests, can be understood as an effect of the discourse about quality, through which backwardness becomes a social category for what deviates from the norm of modernity (Greenhalgh 2003: 199). Although 'backwardness' became closely associated with grandparents in the interview stories, it worked as a designation of everything unattractive. A mother, Zhang Mei, who accorded grandparents little value in matters of childcare, positioned the hospital where she gave birth in similar ways, saying:

I have looked up their methods on the internet. In fact, the technique they use is actually very backward and the data deviates a lot from the real. From my point of view, being an unprofessional, I know that the way they calculate is not scientific. It is useless.

Zhang Mei's words reveal how boundaries constitute norms and deviants. Drawing a line between what is 'scientific' and 'real' approaches on one hand and what is 'back- 
ward' and 'useless' on the other, she establishes this hospital as incompetent. Zhang Mei did not associate incompetence with all experts. On the contrary, doctors and hospitals often were those most trusted. The point is rather that backwardness constitutes something that is absent in this particular hospital and in grandparents more generally, and this something is new scientific knowledge.

\section{THE TRANSFORMATIVE POTENTIAL OF EDUCATION}

As we have seen, infant formula was the object of much critique as something that could damage the child. Not all mothers agreed on the endangering effects of formula, but all agreed that breastfeeding was 'the best'. While grandparents were often designated as those who did not know what was the best, one mother, Jiang Lan, pointed to rural grandparents as being particularly wrong, saying: "Especially in the countryside, even though mothers have no difficulty in breastfeeding their babies, the grandparents might say, 'Oh, we have money. We can buy milk powder to feed the baby'." Here, the assignment of grandparents as backward does not take place in isolation from other categories. Age as a factor is given another dimension when it intersects with origin. In fact, the combination of 'old' and 'rural' seemed to reinforce incompetence. What makes rural grandparents appear 'especially' troublesome might be related to what Ann Anagnost suggests is a broader perception of the countryside as being the epitome of backwardness (Anagnost 1997). The backwardness of rural life was particularly highlighted by another boundary figure, namely the ayi. ${ }^{3}$ The ayi, employed by most mothers, can best be translated as a nanny or dome-stic worker. Although the ayi were a great help in managing daily tasks, they were often ignored or talked about disparagingly in regard to their childcare competences. As one mother, Li Huan, expressed it:

To be honest, nannies don't have much experience, and I think that their way of feeding babies is quite old, out of date, and they're from villages, so they work in Beijing as migrant workers. Sometimes they try to give me advice, but I don't usually take it.

In Li Huan's words, the nanny's 'outdated' doings are linked to her village background. Anagnost has argued that migrant labour in urban China is devalued as of 'low quality' and as such as "an overwhelming obstacle to modernization" (Anagnost 2004: 192). She describes how the discourse about quality unfolds as a designation of two figures in particular: the middle-class child as a sign of quality and the migrant as its lack. That the urban middle-class hires migrant nannies certainly contains class distinctions, but such distinctions can also be seen in their desire for a quality child, which for the middle-class reinforces their distance from the rural, backward population (Anagnost 1997: 199). The mothers' narratives that constantly made a distance to grandparents and nannies might also express a longing for a position associated with the new and modern in contrast to the traditional or old (see also Naftali 2009: 98).

These positions are, however, not fixed. My interviews led me to wonder why two figures were articulated in quite different terms, although at first sight they seemed rather similar - the ayi and the yuesao. 4 The troubled childcare competences associated with the ayi were quite different from the stories about the yuesao, the first-month nursemaid hired to help the mother through the first month after birth by taking care of her and the baby. But how exactly were they different? The yuesao was also from the countryside and often had a background as an ayi. I believe the answer is to be found in the mothers' desires of expert- 
led childcare. The yuesao had training in childcare and, in contrast to the ayi, had written qualifications to prove it. As one mother put it, "when I hire a nanny [yuesao], the nanny has a kind of certificate". Although rural backgrounds throughout the stories appeared as a troubled position, education seemed to have a transformative potential. The yuesao's qualifications meant that she was talked about in quite different terms, as revealed by the words of another mother, Xi Zhilan:

the [yuesao] helped me a lot, she cooked all the meals for me and she gave us considerable knowledge on how to make the baby fall asleep and how to get suitable clothes and how to take medicine and vitamins, and she is as professional as a doctor.

The important aspect of these stories is not so much if the yuesao, the ayi or the grandparents really are incompetent or competent, but how categories are assigned meanings, how boundaries are drawn between these categories and how that helps us to understand what is desirable in terms of mothering and childcare. What we see at first is that rural subjectivities present difficulties, but soon we find that this category is not determinant. Rural subjects are not always backward. Actually we can read $\mathrm{Xi}$ Zhilan's words on the yuesao as an expression of what is intelligible as competent. In the same turn as she qualifies the yuesao as 'professional', another category is demarcated, namely education.

\section{THE COMPETENT MOTHER}

While I have placed particular focus on the distinctions that moved grandparents and nannies to the periphery of competence, in what follows I will look into the competent mother subject. In particular, I explore how the emphasis on expert knowledge positions well-educated mothers as highly intelligible as competent. Stories about the well-educated were told by both mothers and professionals, but the latter were especially explicit about the category. In one of my interviews, a midwife positioned the well-educated in the same turn as she drew a line between easy and difficult patients:

So you know if Chinese women are well-educated they sometimes become mothers late. They spend lots of time studying and working, so when they come to the age when they want a baby, they want to give them the best, so they always search what is the best for them, they think 'oh, breastfeeding is good'. They are eager to learn, they are very good patients. And if you have patients who are young and their family environment is good, they don't need to work as they are from rich families. If they did not have the chance to be educated, it is kind of difficult.

The midwife's words can be read as a distinction between two subjectivities that mothers can assume. While 'a good family environment' could be effective in the making of competent mothering, actually it is likely that it often would do so, the financially safe backgrounds make mothers unprepared for the study practices that are associated with well-educated mothers. As a matter of fact, all the mothers I talked to performed a rather intense information search. One mother in particular, $\mathrm{Ma}$ Chunhua, emphasised the need of expert knowledge to the point that she quitted her job and took an education with an ambition to become a parental consultant. Doing a narrative that tied mothers' competence to high levels of education - and, by extension, to national superiority - she told me:

You know Weibo, ${ }^{5}$ there's a message saying 'Why is Japan better than China now?

Because the child is raised by the mother in Japan', and you know girls in Japan always had a good education, they get bachelor or master degrees and then they quit their jobs and raise their children by themselves, it's 
quite different [from China]. Even if a degree can't explain everything, I think that if one person has a master's or bachelor degree, they must know how to learn, and if one person has this degree and that one has no degree, I'd trust the first to be better to raise the baby.

What concerns Ma Chunhua here is that the competent mother has an ability to learn. This ability was also formulated by a doctor in clinical nutrition, when asked to expand on her ideas about changes in feeding habits, which she had previously identified in relation to the practices of welleducated women. She explained:

The level of education should be an university degree or above at least, I think. Parents with good study habits or skills would [be] more likely to spend time preparing the relevant knowledge on raising happy and healthy babies. They are not just satisfied with knowing how but also why, which makes them constantly search for new information. Meanwhile, less well-educated mothers would easily take the opinions that are there, for example from previous generations, instead of finding the truth by themselves. Or, they don't even have the ability to judge right from wrong. Quite a large number of small children's mothers came to me to check why their children so easily get ill. After a detailed dietary survey, we always see imbalanced dietary structures in the children's daily life. There are some rumours about food choice in China. One of them is that if you cough you'd better not eat any eggs, fish and beef. It is ridiculous, isn't it. But the less educated mothers blindly trust such things.

What the doctor expresses supports Naftali's (2009) point that well-educated mothers are particularly drawn to expert knowledge. In the distinction between mothers with "university degrees" and the "less educated", the latter become incapable of raising "happy and healthy" children.
These mothers apparently lack a study technique and this lack means that they are unable to conform to requirements of new knowledge, but are drawn to old opinions or rumours. This also means that it is not only the old generation or rural people who constitute troubled subjectivities but also those who follow and practise their 'traditional' and scientifically untested ways of raising children. In contrast, welleducated mothers are elevated to an almost unshakeable position of competence. But that position is not totally unassailable, since the constant requirement for new knowledge requires constant work to acquire information in order to become a competent subject. Thus, these positions are not assigned to passive subjects but require continuous reinforcement.

\section{CONCLUSION}

In this article, I have explored how stories about childcare and particularly infant feeding constantly drew boundaries between incompetent and competent subjectivities. The stories are certainly not representative of a general experience of mothering in China. Rather, they provide an insight into a group of urban, well-educated mothers and professionals. This is a group, however, that has been seen as central to the effort of building a modern nation (Anagnost 1997). The stories of mothers and professionals revolved especially around distinctions between those who pursued new knowledge and those who did not. The boundaries can be understood as part of a narrative self-making done by the mothers to indicate a belonging to a group of competent, modern mothers. The distinctions that occurred in their stories can, however, also be seen as part of the broader discourse about quality: as part of a process of modernization in which certain subjectivities make up the margins of the norm (Greenhalgh 2003: 199). While older generations and rural people are spoken of 
as lacking proper knowledge, as out-dated and thus incompetent, well-educated mothers are seen as highly competent due to their abilities in accessing expert knowledge. This does in some ways support other studies that point to the welleducated as those believed to be the best at developing the Chinese nation (see e.g. Woronov 2007). However, I also suggest that boundaries should not be understood as completely stable. There are no "category uniforms" or unchangeable "master identities" (Staunæs 2003b: 103). Rather, the emphasis on education offers troubled subjects opportunities to transform, to gain new, modern knowledge that would make them more intelligible as competent. This instability also applies to the well-educated mothers who cannot just sit back and enjoy their safe position but have to make constant efforts to acquire new information on childcare. As a mother, Li Jiaying, pointed out, she was "learning to be a good mother, still learning that." This emphasis on learning is rather different from ideas of women's 'natural' abilities of childcare that have characterised understandings of motherhood, at least in many western contexts. This is not to say that gender does not matter. Motherhood can be regarded as one of the most gendered identities and the cornerstone in Butler's matrix that makes heterosexual reproduction the very basis for understanding gender norms and intelligible family forms (Butler 1990). Several of the mothers I interviewed also made it clear that they felt in charge of feeding the child, and professionals generally talked about infant feeding as an activity undertaken by the mother, not the father. Moreover, generational conflicts around childcare centred on grandmothers, while grandfathers were left untouched, and the nannies were always women. However, although some mothers and professionals used explanatory models that referred to women's natural abilities in caring, it was not these stories that shaped the dominant narrative. The focus on education and learning opens up more opportunities to pass as competent than a focus on what is natural. Yet, this does not mean that everybody has equal opportunities. Categories are weighted differently and lived life offers a variety of opportunities that not always are aligned with mothers' desires or possibilities of continuous processes of self-education.

\section{Notes}

1. All names are pseudonyms.

2. Further contacts were obtained through the network of a friend and then mainly by asking the people I interviewed for contacts. I conducted most interviews in English, yet in cases where mothers or professionals spoke little or no English I worked with two interpreters. As both interpreters were students interested in gender studies, they took a more active part in the interpretive work than a professional interpreter, who might have a more nuanced language but not necessarily the tools for understanding the variety of meanings.

3. Ayi means 'aunt' but is used to name a housekeeper and/or nanny.

4. Yuesao literally means 'moon sisters-in-law,' but is the name given to the nursemaid, who will take the new mother through the $y$ uezi, or first-month rituals.

5. Weibo equals Twitter.

\section{LITERATURE}

- Anagnost, A. (1997): Children and National Transcendence in China, in: Lieberthal, K. Lin, S. and Young, E. (eds.): Constructing China: The Interaction of Culture and Economics. Ann Arbor: Center for Chinese Studies, Univ. of Michigan. - Anagnost, A. (2004): The Corporeal Politics of Quality (Suzhi), in: Public Culture 16/2.

- Anagnost, A. (2008): 'Imagining Global Futures in China: The Child as a Sign of Value', in: J. Cole and D. Durham (eds): Figuring the Future: Globalization and the Temporalities of Children and Youth. SAR Press. - Avishai, O. (2007): Managing The Lactating 
Body: The Breast-Feeding Project and Privileged Motherhood, in: Qual. Sociol. 30.

- Binah-Pollak, A. (2014): Discourses and practices of child-rearing in China: The bio-power of parenting in Beijing, China Information 2014 28/27. - Butler, J. (1990): Gender Trouble. Feminism and the Subversion of Identity. Routledge, New York \& London.

- Butler, J. (1993): Bodies that matter. On the Discursive Limits of Sex. Routledge, New York \& London.

- Butler, J. (2008): Undoing Gender. Routledge.

New York.

- Bäck-Wiklund, M. (1999): Moderne moderskab, in: L. Dencik. \& P. Schultz Jørgensen (eds.): Børn og familie $i$ det postmoderne samfund. Hans Reitzels Forlag, København.

. Chamberlain, M. (1997): A Baby-Friendly Hospital Initiative in northern China, in: Nurs Ethics $4: 511$.

- Crenshaw, K. (2006): Intersectionality, Identity Politics and Violence Against Women of Color, in: Kvinder, Køn \& Forskning 15/2-3.

- Goh, E. (2011): China's One-Child Policy and Multiple Caregiving. Raising little suns in Xiamen. New York: Routledge.

- Gottschang, S. (2000): A Baby-Friendly Hospital and the Science of Infant Feeding, in: J. Jing (ed.): Feeding China's Little Emperors. Food, Children, and Social Change. Stanford University Press, Stanford California.

- Gottschang, S. (2001): The Consuming Mother: Infant Feeding and the Feminine Body in Urban China, in: N. Chen, C. Clark, S. Gottschang \& L. Jeffery (eds.): Urban China. Ethnographies of Contemporary Culture. Duke University Press, Durham.

- Greenhalgh, S. (2003): Planned births, unplanned persons: "Population" in the making of Chinese modernity, in: American Ethnologist $30 / 2$.

- Hsiung, P. (1995): To Nurse the Young: Breastfeeding and Infant Feeding in Late Imperial China, in: Journal of Family History 20.

- Kipnis, A. (2006): 'Suzhi: A keyword approach', in: The China Quarterly, 186.

- Kukla, R. (2005): Mass Hysteria. Medicine, Culture, and Mothers' Bodies. Rowman \& Littlefield Publishers, Inc. Oxford.

- Law, J. (2000): The Politics of Breastfeeding: Assessing Risk, Dividing Labor, in: Signs, 25/2. - Liamputtong, P. (2010): Performing Qualitative
Cross-Cultural Research. Cambridge University Press, Cambridge.

- Milwertz, C. (1997): Accepting Population Control. Urban Chinese Women and the One-Child Family Policy. Curzon Press, Richmond. - Murphy, E. (2003): Expertise and Forms of Knowledge in the Government of Families, in: The Sociological Review 51/4.

- Naftali, O. (2009): Empowering the Child: Children's Rights, Citizenship and the State in Contemporary China, in: The China Journal 61.

- Naftali, O. (2010): Recovering Childhood: Play, Pedagogy, and the Rise of Psychological Knowledge in Contemporary Urban China, in: Modern China 36.

- National Program of Action for Child Development in China 2000-2010 \& 2011-2020. National Working Committee on Children and Women under the State Council.

http://www.nwccw.gov.cn/html/4l/categorycatid-141.html (located 19.04.2014).

- Phoenix, A. (2006): Interrogating intersectionality: Productive ways of theorising multiple positioning, in: Kvinder, Køn \& Forskning 15/2-3.

- Qiu, L. et al. (2008): A cohort study of infant feeding practices in city, suburban and rural areas in Zhejiang Province, PR China, in: International Breastfeeding Journal 3/4.

- Ross, K. (2012): Faking It: Food Quality in China, in: IJAPS $8 / 2$.

- Staunæs, D. \& Søndergaard, D. M. (2006): Intersektionalitet - udsat for teoretisk justering, in: Kvinder, Kon \& Forskning 15/2-3.

- Staunæs, D. (2003a): Etnicitet, Kon og Skoleliv. Ph.D. dissertation. Roskilde Universitetscenter. - Staunæs, D. (2003b): Where have all the subjects gone? Bringing together the concepts of intersectionality and subjectification, in: NORA $11 / 2$. - Staunæs, D. (2005): From Culturally Avantgarde to Sexually Promiscuous: Troubling Subjectivities and Intersections in the Social Transition from Childhood into Youth, in: Feminism \& Psychology 15.

- Woronov, T. (2007): Chinese Children, American Education: Globalizing Child-Rearing in Contemporary China, in: J. Cole \& D. Durham (eds.): Generations and Globalization: Youth, Age, and Family in the New World Economy. Bloomington, Indiana, United States: Indiana University Press. - Yuval-Davies, N. (2006): Belonging and the politics of belonging, in: Patterns of Prejudice 40/3. 